\title{
Price Regulation in a Vertically Integrated Natural Gas Industry: The Case of Mexico
}

\author{
DAGOBERT L. BRITO \\ Department of Economics and Baker Institute, Rice University \\ JUAN ROSELLÓN * \\ Centro de Investigación y Docencia Económicas (CIDE)
}

\begin{abstract}
The Comisión Reguladora de Energía of Mexico has implemented a netback rule for linking the Mexican natural gas price to the Texas natural gas benchmark price in an industry structure characterized by a vertically integrated state-owned monopoly. This paper shows that in an open economy where agents can choose between gas and alternative fuels, and where the density function describing the distribution of agents along the pipeline can have mass points, the netback rule is Pareto optimal.
\end{abstract}

\section{Introduction}

The Mexican oil and gas market is a peculiar one. The national State firm Petróleos Mexicanos (Pemex) has a monopoly in production of oil, gas and natural gas liquids, and it is vertically integrated in transportation and marketing of these products. ${ }^{1}$ Furthermore, gas is a joint product of oil, a fact that makes impossible the allocation of production costs to natural gas alone. ${ }^{2}$ In addition, public ownership of energy resources in Mexico is

\footnotetext{
* Contact author. Department of Economics, CIDE, Carret. México-Toluca 3655, Lomas de Santa Fé, C.P. 01210, México D.F. Mexico. Email juan.rosellon@cide.edu We would like to thank William Laney Littlejohn for his suggestions, as well as two anonymous referees for insightful comments. All remaining errors are our own. The research reported in this paper was supported by grants for the Baker Institute for Public Policy at Rice University, and the Comisión Reguladora de Energía to CIDE. Juan Rosellón carried out this research while he was a visiting Senior Fellow at the Kennedy School of Government of Harvard University and acknowledges support from the Repsol-YPF-Harvard Kennedy School Fellows Program, the Fundacion Mexico en Harvard, and the Harvard Electricity Policy Group.

${ }^{1}$ A partial reform in 1995 permitted new private transportation and distribution projects, but maintained Pemex' monopoly in production. This reform has only been successful in attracting private investment to distribution systems (see Rosellón and Halpern, 2001).

${ }^{2}$ See Adelman (1963) and Brito, et. al. (2000). The main substitutes for natural gas in Mexico are liquid petroleum gas (LPG) for residential consumption, and fuel oil and diesel for industrial consumption and power generation. Since the marginal cost of production for these products cannot be isolated, their prices are usually determined through international benchmarks that are not correlated with the natural gas price
} 
politically critical. Foreign firms originally owned the oil industry and its nationalization was considered as a symbol of Mexican sovereignty. Nowadays, privatization of Pemex would be unthinkable in political terms.

Technical and institutional difficulties are thus important problems in regulating the Mexican natural gas price. The Mexican regulator, Comisión Reguladora de Energía (CRE), solved the problem by using a natural gas price benchmark in Southeast Texas. The natural gas price at Ciudad Pemex in Southeast Mexico (where $80 \%$ of total natural gas is produced as a byproduct of oil extraction) is linked to the price at the Houston Ship Channel hub through a netback formula. The price of gas in Ciudad Pemex is equal to the price at Houston plus transport costs from Houston to the arbitrage point, (the arbitrage point is currently located at Los Ramones, in northeast Mexico $)^{3}$ minus transport costs from the arbitrage point to Ciudad Pemex (see Figure 1). ${ }^{4}$

This pricing regulatory formula is an implementation of the Little-Mirrlees method, which proposes the use of world prices for pricing traded goods. ${ }^{5}$ Thus the price of gas in Houston is a measure of the opportunity cost to Mexico of consuming the gas rather than exporting it to the United States. ${ }^{6}$ The netback rule also implies that the Mexican gas price remains insensitive to variations in demand for gas in Mexico, and that consumers are facing a flat supply curve. The amount of gas imported or exported works as an equilibrating factor.

The netback rule was published by the CRE in $1996 .^{7}$ It has been debated during several North American price spikes such as the one in December of 2000. ${ }^{8}$ The price of gas in Houston rose from around $\$ 2.00$ per MMBTU in January 2000 to almost $\$ 10.00$ per MMBTU by January 2001. Many Mexican firms had not hedged and as a result found themselves in serious trouble. Plants were being forced to close. There was strong pressure on the CRE to drop the Houston benchmark in pricing gas. Pemex rescued the firms in trouble by offering a $\$ 4.00$ per MMBTU three year take or pay contracts. The netback rule based on the Houston price remained.

In this paper, we study the economics of the netback rule in a general model. It will be shown that under a very general set of assumptions, the netback rule is Pareto efficient.

\section{The Mexican natural gas transportation system}

The Mexican pipeline system is 9,043 kilometer long and reaches most of the main industrial centers in the South, Center and Northeast of the country (see Figure 1). Of the

(see Brito et al, 2000). Thus, the price of natural gas cannot be determined through the price of its substitutes. However, using the price in Houston implicitly makes the price of Mexican natural gas reflect the price of competitive sources of energy.

${ }^{3}$ The arbitrage point is the place where northern and southern gas flows meet, and where northern and southern gas prices coincide. The location of the arbitrage point might change according to gas flows. For example, if more gas is imported it will tend to move southwards displacing the arbitrage point from its current location at Los Ramones to the next demand point, Cempoala, which is located 700 kilometers to the south.

${ }^{4}$ See Comisión Reguladora de Energía (1996), section 4.

${ }^{5}$ See Little and Mirrlees (1968) p. 92.

${ }^{6}$ See Brito and Rosellón (2002).

${ }^{7}$ Pemex had been using a very similar rule base on another Texas benchmark (Tetco and Valero). See Rosellón and Halpern (2001).

${ }^{8}$ See Arteaga, and Flores (2002) and Arteaga and Flores, (2003). 
total natural gas transported in the system during 2000, $69 \%$ was associated gas, $24 \%$ was non-associated gas, and 7\% was imported gas. As of 2000, 1795 kilometer of new private pipelines had been added to the existing transportation system and the capacity had increased to $7.4 \mathrm{bcfd}$. Additionally, the pipeline linkage from the Reynosa-Burgos area to the Texas market is under expansion. ${ }^{9}$

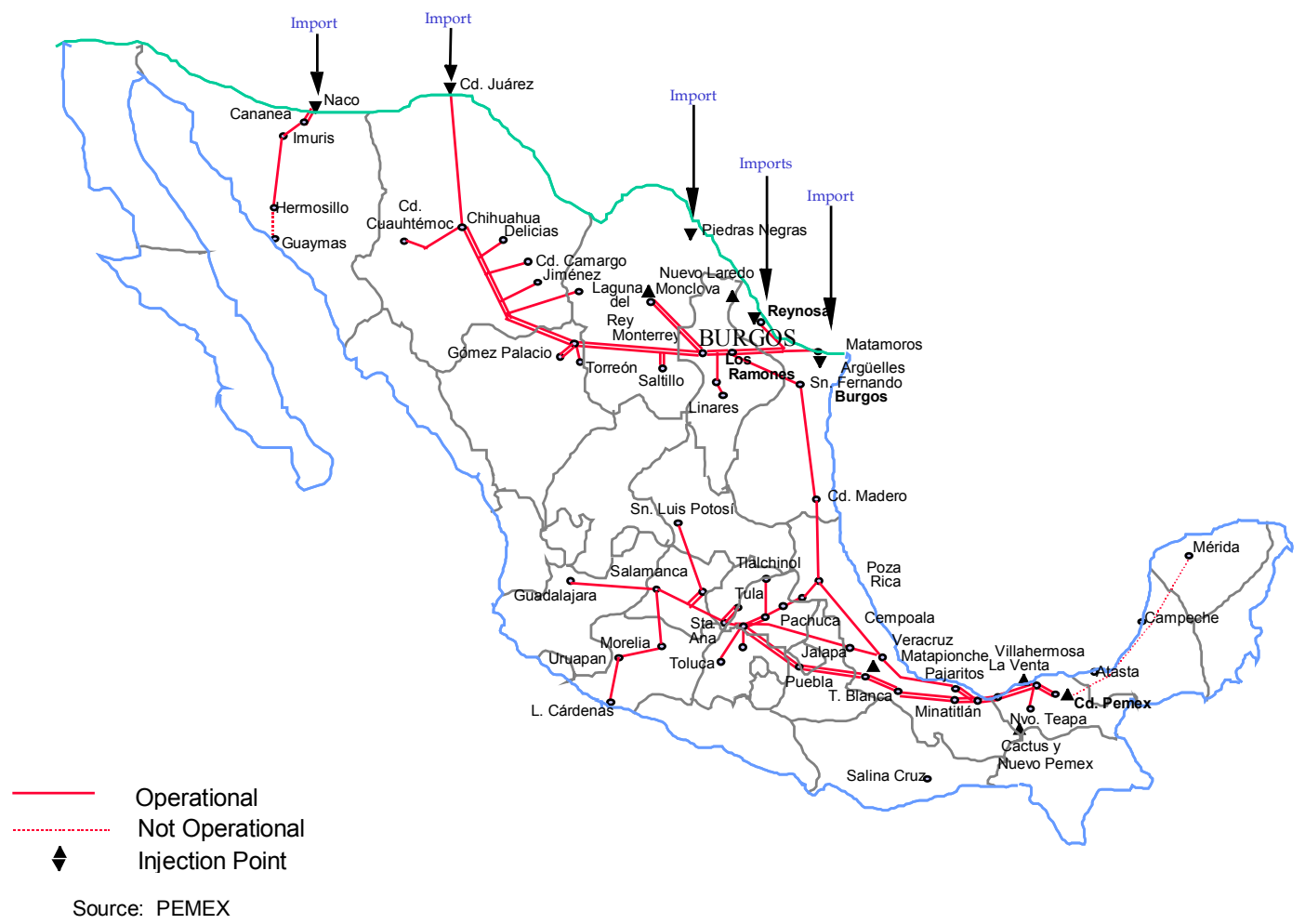

\section{Figure 1}

The pipeline system in Figure 1 can be considered as a single pipeline connecting production in the South with production in the North. Ciudad Pemex is located at the south end of the system and produces most of natural gas (more than $80 \%$ of total gas) as associated gas (that is as a by product of oil extraction) $)^{10}$, while Reynosa-Burgos is located at the north end. Burgos produces $17.3 \%$ of total natural gas production and is a link to the Texas pipeline system. Two branches complement the pipeline system. One branch connects Ciudad Juárez (a place where gas is imported) and Los Ramones (the junction of the Southeast, Northwest and Northeast pipelines). The other branch of the pipeline connects the cities in the center of the country (including Mexico City) with the main network at Cempoala.

The analysis of this pipeline network can be simplified exploiting the technical and institutional properties of the system. As shown in Brito and Rosellón (2002), the problem

\footnotetext{
${ }^{9}$ The export-import capacity at the Reynosa sector for 2002-2003 was 534 MMcfd.

${ }^{10}$ This means that it is impossible to allocate costs of production (or extraction) to most of natural gas produced in Mexico (see Adelman, 1963).
} 
of pricing gas can be analyzed as a single pipeline connecting Burgos with Ciudad Pemex. The connections at Los Ramones and Cempoala are mass points in the distribution of demand.

The netback rule follows from the solution of the problem of a regulator that maximizes welfare subject to resource constraints in the pipeline network. The optimal prices of natural gas are the shadow prices in the optimization associated with the production of natural gas in Mexico. In particular, the neback rule is the shadow price of the scarcity constraint at Ciudad Pemex. This rule follows from the condition that Pemex should be indifferent between the sale or purchase of gas in Houston, and the sale of gas at any point in Mexico. When this condition is not met, the construction of a welfareimproving allocation of gas could be feasible. It would be enough to shift the allocation of gas from activities whose marginal benefit is less than the price of gas to activities whose marginal benefit is higher than the price of gas.

We next study the netback rule in a general model. We will assume that individuals are located along a pipeline. They can spend their income on goods, an alternate fuel or gas. The price of gas is given by a nonlinear price schedule that is a function of location and the quantity of gas purchased. We show that under such conditions, the general optimal price of gas is the netback rule. A general optimal nonlinear price schedule for gas is a very powerful instrument in that it permits location specific taxation. However, the netback rule is also optimal without location specific charges if there are no income effects. Further, the netback rule is always Pareto efficient. The netback rule is the optimal way of pricing gas unless there are redistributional goals that must be met using this instrument and location specific charges are ruled out.

\section{$3 \quad$ Model}

Assume that individuals are located on the interval $[0, \bar{n}]$ with a general density function $f(s) \geq 0$ which represents a pipeline of length $\bar{n}$. This density function allows the possibility of intervals with no demand as well as mass points. A special case is where demand is on a set of discrete points along the pipeline. The typical individual located at point $s$ has a utility function of the form.

(1) $v=u(x, y, z)$ 
where $x$ is a bundle of goods, $y$ is the consumption of natural gas and $z$ is the consumption of a substitute fuel for natural gas. ${ }^{11}$ Each individual is assumed to furnish one unit of labor at a wage $w(s)$.

Individuals maximize utility subject to the constraint

$w(s)=x+t(y, s)+q(s) z$

where $t(y, s)$ is the price schedule for gas and $q(s)$ is the market determined price of the substitute fuel. The price of $x$ is normalized to one.

The planner can redistribute income by location as a function of the consumption of gas, so $\frac{\partial t(y, s)}{\partial s}$ is a possible control instrument. Define $\alpha(y, s)=\frac{\partial t(y, s)}{\partial s}$. Individuals differ in their location and income, so using the envelope theorem it follows that the utility of individuals along the pipeline is given by the solution of the following differential equation (see the Appendix for the derivation of differential equation (3) and of most of the further mathematical derivations):

(3) $\frac{d v}{d s}=\frac{\partial u(x, y, z)}{\partial x}\left[\frac{d w(s)}{d s}-\alpha(y, s)-z(s) \frac{d q(s)}{d s}\right] \cdot{ }^{12}$

Let $v(s)$ be the solution of the differential equation, then we can use the relationship $v=u(x, y, z)$ to write

(4) $x=x(v, y, z)$.

The variable $v(s)$ is a state variable and the variables $y(s)$ and $z(s)$ are control variables. Define the aggregate amount $x$ by $\mathrm{X}$, of $y$ by $Y$ and $z$ by $\mathrm{Z}$. The good $X_{1}$ is consumed and $X_{2}$ is exported. For gas, $Y_{0}$ is produced domestically, $Y_{1}$ is imported at a price $p, Y_{2}$ is used to produce $X, Y_{3}$ is imported gas consumed by individuals and $Y_{4}$ is domestic gas consumed by individuals. For the substitute fuel, $Z_{1}$ is imported at a price $\bar{q}$, $Z_{2}$ is used to produce $X$ and $Z_{3}$ is consumed by individuals.

We will assume that the good $X$ is produced by a technology that uses energy

(5) $X=F\left(Y_{2}, Z_{2}\right)$

\footnotetext{
${ }^{11}$ As with natural gas, these main substitute goods (LPG, diesel and fuel oil) are also byproducts of oil extraction. Therefore, the supply of these products are conditioned by Pemex' role as a source of revenue for the Mexican government (see Rosellón and Halpern, 2001).

${ }^{12}$ Note that we are implicitly assuming that $\partial u / \partial x$ is positive (a standard assumption for unsatiated goods) in order to invert $v=u(x)$ to get $x=x(v)$.
} 
where $F\left(Y_{2}, Z_{2}\right)$ is a well behaved strictly concave function, and $Y_{2}$ and $Z_{2}$ is the energy used to produce the good. Production of good $x$ is assumed to occur at $n=0$ and it is assumed that good $x$ can be transported without charge (see figure 2$)^{13}$.

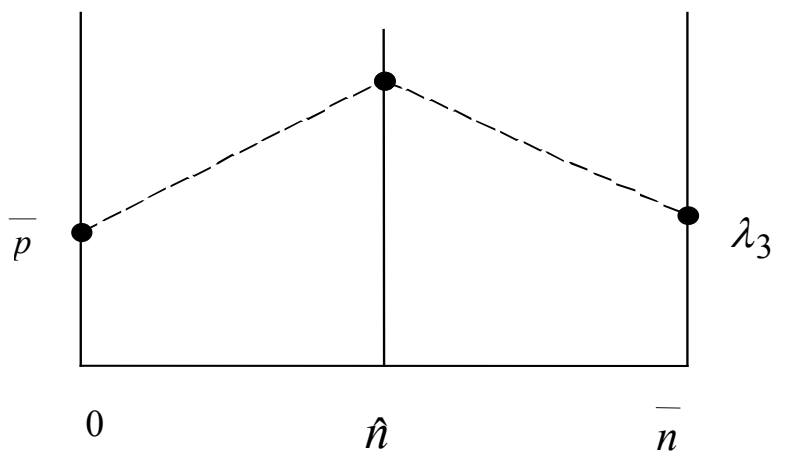

\section{Figure 2}

Production of natural gas is a joint product of oil extraction (associated gas) and is assumed to occur at $n=\bar{n}$, while natural gas is imported at $n=0$. It is also assumed that gas can be transported at $\operatorname{cost} c$. Define $n$ as the point of arbitrage. The cost of moving imported gas to point of arbitrage is $\hat{n} c$ and the cost of moving domestic gas to point of arbitrage is $(\bar{n}-\hat{n}) c$.

Define

(6) $V=\int_{0}^{n}[\beta(s) v(s)-s c y(s)] f(s) d s+\int_{n}^{\bar{n}}[\beta(s) v(s)-(\bar{n}-s) c y(s)] f(s) d s$

where $\beta(s)$ is the welfare weight of individuals located at point $s$. Now let us consider a planner trying to maximize welfare

(7) $W=V+G$

where $G$ are public expenditures. The maximization is subject to the constraints that

(8) $X_{1}=\int_{0}^{\pi} x(s) f(n) d s$

${ }^{13}$ As we explain later in the paper, $\lambda_{3}$ is the shadow price of domestic natural gas at the point of production. 
(9) $Y_{3}=\int_{0}^{n} y(s) f(n) d s$

(10) $Y_{4}=\int_{n}^{n} y(s) f(n) d s$

(11) $Z_{3}=\int_{0}^{\bar{n}} z(s) f(n) d s$

Equations (8) through (11) represent the aggregate demand for goods and energy. If we assume that net redistribution is zero, then

(12) $0=\int_{0}^{\bar{n}} \alpha(s) f(n) d s$

The aggregate constraints are:

(13) $X_{1}+X_{2}+G=F\left(Y_{2}, Z_{2}\right)$

(14) $Y_{0}+Y_{1}=Y_{2}+Y_{3}+Y_{4}$

(15) $Z_{1}=Z_{2}+Z_{3}$

(16) $X_{2}-p Y_{1}-\bar{q} Z_{1}=0$

Constraints (13) through (15) make supply and demand equal in the markets for the private good, natural gas and the substitute fuel, respectively. Equation (16) represents the balance between the value of exports and imports. The constraints given by equations (8) through (12) can be converted to differential equations

(17) $\frac{d X_{1}}{d n}=x(n) f(n)$

(18) $\frac{d Y_{3}}{d n}=y(n) f(n)$

for $n<\hat{n}$, 
(19) $\frac{d Y_{4}}{d n}=y(n) f(n)$

for $n>\hat{n},{ }^{14}$

$$
\frac{d Z_{3}}{d n}=z(n) f(n)
$$

(21) $\frac{d A}{d n}=\alpha(n) f(n)$

where $A$ is aggregate redistribution. The aggregate constraints given by (13) to (16) define the transversality conditions for the differential equations. The planner's problem can be written as maximizing the sum of aggregate welfare $V$ and public expenditures $G$ subject to the aggregate constraints (13) through (16):

$$
W=V+G+\delta_{1}\left[F\left(Y_{2}, Z_{2}\right)-X_{1}-p Y_{1}-\bar{q} Z_{1}-G\right]+\delta_{2}\left[Y_{0}+Y_{1}-Y_{2}-Y_{3}-Y_{4}\right]+\delta_{3}\left[Z_{1}-Z_{2}-Z_{3}\right]
$$

The variables $\delta_{i}, i=1,3$ are the Lagrange multipliers associated with the aggregate constraints. This is an optimal control problem and the maximization with respect to the aggregate variables provides the transversality conditions. The Hamiltonian is:

$$
H=\beta v+\left[\lambda_{1} x+\left(\lambda_{2}-c n\right) y+\lambda_{4} z+\lambda_{5} \alpha\right] f(n)+\theta \frac{\partial u}{\partial x}\left(\frac{d w}{d n}-\alpha-z \frac{d q}{d n}\right)
$$

for $n<\hat{n}$ and

$$
H=\beta v+\left\{\lambda_{1} x+\left[\lambda_{3}-c(\bar{n}-n)\right] y+\lambda_{4} z+\lambda_{5} \alpha\right\} f(n)+\theta \frac{\partial u}{\partial x}\left(\frac{d w}{d n}-\alpha-z \frac{d q}{d n}\right)
$$

for $n>\hat{n}$, where $\lambda_{i}, i=1,5$, are the costate variables associated with (17) through (21) respectively, and $\theta$ is the costate variable associated with (3). The control variables are $y$, $z$ and $\alpha$.

\footnotetext{
${ }^{14}$ If $f(\hat{n})$ is a mass point in the distribution function the demand for domestic gas will be such that $Y_{0} \leq Y_{4}$
} 


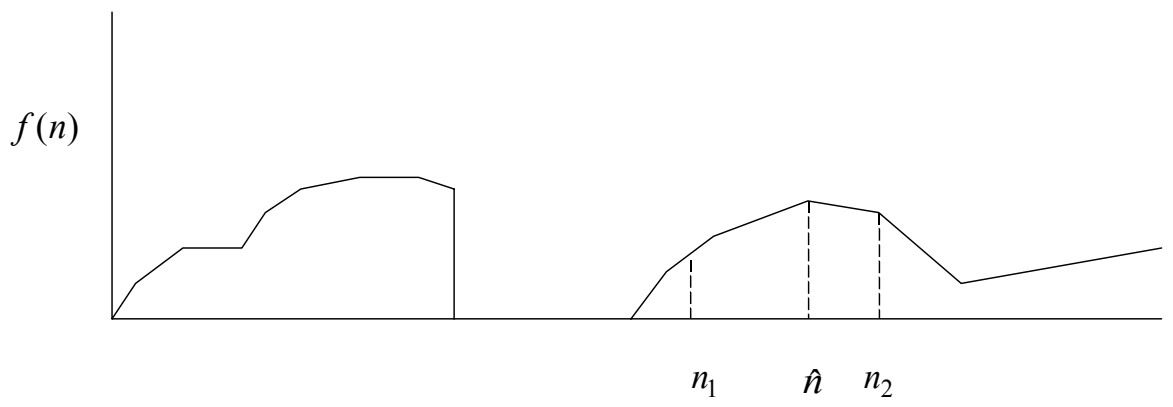

Figure 3

We assume that the point $\hat{n}$ is in an interval $\left(n_{1}, n_{2}\right)$ such that $f(n)$ is strictly positive, continuous and there are no mass points for $n$ in $\left(n_{1}, n_{2}\right)$ (see Figure 3 ). Then it follows from the continuity of the Hamiltonian that

$$
\left(\lambda_{2}-c \hat{n}\right)=\left(\lambda_{3}-c(\bar{n}-\hat{n})\right)
$$

Equation (23) links the shadow price of imported gas with the shadow price of domestic gas given the assumption that there are no mass points. Now suppose that $\hat{n}$ is a mass point. Then imported gas and domestic gas are both consumed at $\hat{n}$ and it follows from the first order conditions with respect to $y$ that

$$
\left(\lambda_{2}-c \hat{n}\right)=\left[\lambda_{3}-c(\bar{n}-\hat{n})\right]
$$

which is identical to equation (23) and thus yields the netback rule. Intuitively the result follows from the law of one price. If imported gas and domestic gas are being sold at the point represent by $\hat{n}$, they must have the same price.

The value of $\lambda_{3}$ is derived from (23) and results in

$$
\lambda_{3}=-p-2 c \hat{n}+c \bar{n}
$$

Since $\lambda_{3}$ is the shadow price of equation (19) or, in other words, the shadow price of domestic gas at the point of production, this is in fact the netback rule.

Proposition 1 The optimal non-linear price schedule for natural gas is the netback rule. Proof (see Appendix)

Proposition 2 If all individuals have equal weight in the aggregate utility function and there are no income effects, the optimal non-linear price schedule for natural gas is the netback rule and it is independent of redistribution.

Proof (see Appendix) 
Proposition 3 The netback rule for pricing natural gas is Pareto optimal. Proof (see Appendix)

These three propositions establish several optimality characteristics of the netback rule. Proposition 1 states that when in fact there exist no constraints in the flow of gas, gas will flow in equilibrium so that the marginal rate of substitution between the private good and gas is equal to the netback rule.

Proposition 2 states that when there are no income effects ${ }^{15}$ the price of gas will be equal to the netback rule. Since all individuals have the same welfare weights and there are no income effects the aggregate welfare function will not be sensitive to redistribution.

Proposition 3 states that given any allocation that results from the netback rule, then we can find a set of weights $\beta(n)$ in the welfare function so that $\theta(n)=0$ for all $n$. Recall that $\theta(n)=\frac{\partial V}{\partial u(n)}$ is the contribution to the aggregate welfare of increasing the utility of an individual located at $n$. So, when $\theta(n)=0$ for all $n$ it gives a first best. Therefore, the given allocation maximizes welfare and any deviation will not be optimal so that the allocation corresponds to the Pareto optimum for the set of weights.

\section{$4 \quad$ Vertical integration and the netback rule}

PEMEX is vertically integrated among production, transportation and marketing activities in the natural gas industry. This potentially permits PEMEX to carry out several strategies so as to preserve its vertical monopoly as well as to control pipeline capacity so as to circumvent the netback formula. When there is not enough capacity, the gas movement would not clear the markets, and Pemex could capture the rents associated with the capacity restriction.

Vertical integration between transportation and marketing lets PEMEX' transportation subsidiary ("PMX-Trans") offer a preferential treatment to its marketing subsidiary ("PMX-Com") ${ }^{16}$ regarding access to capacity and transportation tariffs. This allows PMXCom preserve its monopoly in gas marketing ${ }^{17}$ and, more importantly, avoid the netback rule. More specifically, PMX-Trans monopolistically offers access to its pipeline capacity. This service is supplied to PMX-Com as well as to potential private competitors in a supposedly contestable market. However, if open access clauses are not carefully enforced by the regulator, PEMEX might allocate most of its capacity and gas sales to PMX-Com,

\footnotetext{
${ }^{15}$ So that the second term of (33) is equal to zero.

${ }^{16}$ PEMEX' natural gas transportation functions are carried out by the "Pipeline Area" of PEMEX' subsidiary Pemex Gas y Petroquímica Básica (PGPB). PEMEX' gas marketing functions are performed by PGPB's "Natural Gas Area" while international marketing activities are made by PEMEX' international subsidiary (PMI)

${ }^{17}$ PEMEX is able to exert its monopoly because the slight differences between marketing products (especially in financial futures markets) makes very difficult to technically prove that two marketing products are identical. For example, PEMEX might sell gas for a delivery 30 days in the future at a given price and the next day sell gas for delivery 29 days in the future at a different price. Technically, this transactions would not be discriminatory and would be very difficult to monitor by the regulator. The CRE actually tries to regulate Pemex' gas marketing activities through requiring detailed information on PEMEX' gas marketing, transportation and storage activities as well as gas sales, prices, contracts, availability, imports, exports, national balance, and price discount methods.
} 
and argue lack of capacity to meet gas sales to other consumers at a regulated price. PMXCom could then sell gas at a price above the netback price. Even more, under constraints of capacity, Pemex could use cross subsidization from gas production and transportation activities to marketing activities so as to be able to further increase the final gas price.

As an example on how a capacity pipeline constraint would be reflected in the final gas price, let us analyze the case of a capacity constraint in the import pipeline capacity. In such a case, it would be necessary to add a constraint, $\bar{Y}_{1}$, for natural gas imports to optimization problem (22). This can be rewritten as:

$$
W=V+G+\delta_{1}\left[F\left(Y_{2}, Z_{2}\right)-X_{1}-p Y_{1}-\bar{q} Z_{1}-G\right]+\delta_{2}\left[Y_{0}+Y_{1}-Y_{2}-Y_{3}-Y_{4}\right]+\delta_{3}\left[Z_{1}-Z_{2}-Z_{3}\right]+d_{4}\left[\bar{Y}_{1}-Y_{1}\right]
$$

where $\delta_{4}$ is the Lagrange multiplier for the import constraint and, when it is binding, it will be reflected in the natural gas price. This multiplier reflects rents to the control of access to the pipeline and exemplifies the more general proposition that, when there are pipeline capacity bottlenecks, the Lagrange multiplier associated with the pipeline capacity constraint reflects such rents. In such a case, the netback rule will not work since gas flows cannot equilibrate the market, and the gas price would have to be adjusted so that rents accrue to the scarce factor: pipeline capacity.

PEMEX' vertical disintegration would contribute to a more competitive allocation of pipeline capacity, and hence to a better performance of the netback price regulation. However, institutional and political constraints preclude the vertical divestiture of Pemex. Alternatively, as argued by Brito and Rosellon (2003a), Pemex could equivalently be only allowed to establish gas spot or future contracts as long as it does not carry out any discount in the regulated production prices and transportation tariffs inside Mexico, even in a non discriminatory way. Pemex would then concentrate its marketing activities in the Houston market exclusively. ${ }^{18}$ Likewise, the CRE should enforce open access regulation as well as the monitoring of PEMEX' investment in pipeline capacity.

\section{$5 \quad$ Other Policy Implications of the Netback Rule}

We have shown that the netback rule results from a well structured welfare maximization general model, and hence has several desirable efficiency properties. However, policy makers should be aware that the netback rule also defines a peculiar structure of incentives. Small changes in the distribution of gas might result in big changes in its price. Pemex could then divert production from the regulated market (or simply reduce its production) to bring south the arbitrage point, and then cause an increase of the domestic natural gas price twice greater than the change in the marginal cost of transport. ${ }^{19}$ This does

\footnotetext{
${ }^{18}$ Brito and Rosellón (2003a, p.18-20) show that it is Kaldor-Hicks superior to have the price of gas in Mexico equal to the Houston netback price and have Pemex sell the balance of the gas in the Houston market rather than sell gas in Mexico at a price below the Houston netback price

${ }^{19}$ From equation (24) we get $\frac{\partial \lambda_{3}}{\partial n}=-2 c$ Then, for example, a $700 \mathrm{~km}$ southward displacement of the arbitrage point from Los Ramones (its current location) down to Cempoala (the next demand mass point)
} 
not change the efficiency properties of the netback rule, but it does change the allocation of economic rents. Policy makers should consider this when implementing location changes of the arbitrage point. ${ }^{20}$

Other policy measures that might have an effect on the netback rule include reductions in import tariffs, export restrictions and investments in production facilities. A reduction in import tariffs does not imply an increase in natural gas imports and has a small effect on the domestic gas price (proportional to the tariff reduction). A pipeline capacity restriction that hinders gas exports is reflected in the domestic gas price through the shadow price of such a restriction. Additionally, the development of new gas production sites close to the arbitrage point - and possibly not close to consumption areas - is socially optimal. ${ }^{21}$

One more discussion on the netback rule is with respect to the benchmark price. The use of the South Texas price introduces to the Mexican market the competition of the US natural gas market but it also introduces the volatility of that market, as has been experienced in several cold winters. Then the netback rule must also be implemented with hedging mechanisms that smooth out such price distortions. Mexico has both followed decentralized and centralized policy measures regarding hedging procedures. However, Mexican industrial consumers have kept pressing the government so as to get gas price reductions. ${ }^{22}$ They would like to substitute the current Texas price reference with a (lower) "Mexico price" that takes an average of the international natural gas prices. Would such a policy be reasonable?

The structure of the netback formula represents the value of domestic natural gas in a welfare maximization model. Likewise, the opportunity cost of the Mexican natural gas is given by the Texas gas price and not by other international markets (say in South America or Europe) because pipeline natural gas markets are local or regional. Natural gas is methane, it becomes liquid at very low temperatures (around $-275^{\circ} \mathrm{F}$ ) and liquid natural gas (LNG) an only be transported by sea at a high cost. ${ }^{23}$ Therefore pipeline natural gas is not a typical commodity that can use any international price as a benchmark to determine its opportunity cost.

However, there exists the theoretical possibility of changing the parameters of the formula and, consequently, modify the distribution of the rents associated with domestic

would increase the domestic natural gas price from USD0.50 to USD0.75 per MMBTU, which would imply an increase in Pemex annual rents in around USD170 million.

${ }^{20}$ Brito and Rosellón (2003b) propose two short-term measures that the CRE might use to provide PEMEX with incentives to increase supply in the domestic regulated market (and hence avoid a deliberated southwards displacement of the arbitrage point). The first measure is to temporally fix the arbitrage point at Los Ramones so that Pemex increases production (and investment) to a level corresponding to the price of gas implied by Los Ramones. The second strategy is to set a price based on the netback rule for internal gas transactions among PEMEX' subsidiaries. Brito and Rosellón show that, although these measures can be at odds with long-run Pareto efficiency, their effects are minimal in the short run and help to deal with political pressures to keep domestic gas price low.

${ }^{21}$ See Brito and Rosellón (1998)

${ }^{22}$ Mexican consumers - as any other consumers in North America - could hedge in the developed US natural gas market (in particular the Houston market). However, political pressure by Mexican industrial consumers has proven to be effective. In addition to ask for a lower price for Mexican gas (unrelated to the netback rule), they have also put pressure so as to receive implicit subsidies through governmental hedging mechanisms. For example, the Mexican government implemented in 2001 three-year take-or-pay hedging contracts offered by Pemex with a fixed price of 4 dollars per Mmbtu, which eliminated any potential competition from private gas marketers.

${ }^{23}$ LNG projects only become economical when the long-run price of pipeline natural gas is more than approximately USD4.00 per MMBTU. 
natural gas sales. Therefore, a change of the benchmark price from Texas to, say, Venezuela would transfer rents from Pemex (and, hence, from the public budget) to natural gas consumers. This price-distortion policy would evidently be an inferior transfer policy to a lump-sum subsidy to such consumers. ${ }^{24}$

Nonetheless, the efficiency of using the Houston price as a benchmark relies on the assumption of competitive conditions in the Texas natural gas market. If such assumption does not hold, then the use of an alternative price might be justified. The recent increasing trend in the gas price and the expected future increase of LNG imports to the North American market might give good reason for the use of an alternative benchmark price. If it can be proved that pipeline network capacity restrictions in Texas preclude the arbitrage between the LNG import price and the Houston natural gas price, then the use of a net present lower benchmark price (that considers the possibly lower future gas price resulting from the increased entrance of LNG to the Texas market) might be justified.

\section{$6 \quad$ Concluding remark}

This paper studies the optimality of the netback rule based on the Houston Ship Channel price to price natural gas in Mexico that has been implemented by Comisión Reguladora de Energía in an open economy where agents can chose between gas and alternative fuels, and where the density function describing the distribution of agents along the pipeline can have mass points. The paper shows that the netback rule is Pareto optimal. However, a challenging policy issue for the adequate performance of the netback rule is the vertical disintegration of Pemex' transportation and marketing activities so as to assure the existence of enough capacity on the Pemex' pipeline network. As discussed, when there is not enough capacity the gas flows will not clear the markets, the netback rule will not work, and Pemex will capture the rents associated with the capacity bottlenecks.

\section{$7 \quad$ References}

Adelman, M.A (1963) The Supply and Price of Natural Gas. Oxford B. Blackwell.

Arteaga, J. C. and D. Flores (2002) "Una Nota sobre la Regulación del Precio del Gas en Mexico," El Trimestre Economico, vol. LXIX(1), No. 273: 115-121.

Arteaga-García, Julio César; Flores-Curiel, Daniel (2003) "Debe ser Texas la Referencia para fijar el Precio del Gas en México?" EAWP2(10). http://eawp.economistascoruna.org/archives/vol2n10/.

Brito, D. L. and J. Rosellón (1998) "Pricing Natural Gas in Mexico," CIDE Working Paper, E-120.

Brito, D. L. and J. Rosellón (2002) "Pricing Natural Gas in Mexico: An Application of the Little-Mirrlees Rule," The Energy Journal, 23: 81-93.

\footnotetext{
${ }^{24}$ Additionally, the social-welfare superiority of a government transfer to gas consumers as opposed to other
} social goals should also be gauged. 
Brito, D.L. and J. Rosellón (2003a) "Regulation of Gas Marketing Activities," Estudios Económicos, 18: 15-35.

Brito, D.L. and J. Rosellón (2003b) "Strategic Behavior and the Pricing of Gas in Mexico," CIDE Working Paper, E-259.

Brito, D. L., W. L. Littlejohn, and J. Rosellón (2000) "Pricing Liquid Petroleum Gas in Mexico," Southern Economic Journal, 66: 742-753.

Comisión Reguladora de Energía (1996) "Directiva sobre la Determinación de Precios y Tarifas para las Actividades Reguladas en materia de Gas Natural," http://www.cre.gob.mx.

Little, I.M.D. and J.A. Mirrlees (1968) Manual of Industrial Project Analysis in Developing Countries. Paris: Development Centre of the Organization for Economic CoOperation and Development.

Rosellón, J. and J. Halpern (2001) "Regulatory Reform in Mexico's Natural Gas Industry: Liberalization in Context of Dominant Upstream Incumbent," Policy Research Working Paper 2537, The World Bank.

\section{$8 \quad$ Appendix}

\subsection{First order conditions for maximization of (1) subject to (2)}

The Lagrangian for the individual's maximization is:

(26) $L=u(x, y, z)+\lambda[w(s)-x-t(y, s)-q(s) z]$

Then if we assume that there are no corner solutions, the first order conditions $\operatorname{are}^{25}$ :

(27) $\frac{\partial u(x, y, z)}{\partial x}-\lambda=0$

(28) $\frac{\partial u(x, y, z)}{\partial y}-\lambda \frac{\partial t(y, s)}{\partial y}=0$

(29) $\frac{\partial u(x, y, z)}{\partial z}-\lambda q(s)=0$

Using the first order condition for $x$, the differential equation:

(30) $\frac{d v}{d s}=\lambda\left[\frac{d w(s)}{d s}-\alpha(y, s)-z(s) \frac{d q(s)}{d s}\right]$

\footnotetext{
${ }^{25}$ This assumption does not change any of the results.
} 
can be rewritten as:

$$
\frac{d v}{d s}=\frac{\partial u(x, y, z)}{\partial x}\left[\frac{d w(s)}{d s}-\alpha(y, s)-z(s) \frac{d q(s)}{d s}\right]
$$

\subsection{First order conditions for maximization of (22) with respect to aggregate constraints (13) through (16)}

To simplify notation we will not use the arguments of the variables. The Hamiltonian is

$$
H=\beta v+\left[\lambda_{1} x+\left(\lambda_{2}-c n\right) y+\lambda_{4} z+\lambda_{5} \alpha\right] f(n)+\theta \frac{\partial u}{\partial x}\left(\frac{d w}{d n}-\alpha-z \frac{d q}{d n}\right)
$$

for $n<n$ and

$$
H=\beta v+\left\{\lambda_{1} x+\left[\lambda_{3}-c(\bar{n}-n)\right] y+\lambda_{4} z+\lambda_{5} \alpha\right\} f(n)+\theta \frac{\partial u}{\partial x}\left(\frac{d w}{d n}-\alpha-z \frac{d q}{d n}\right)
$$

for $n>\hat{n}$, where $\lambda_{i}, i=1,5$, are the costate variable associated with (17) through (21) respectively and $\theta$ is the costate variable associated with (3). The control variables are y, $z$ and $\alpha$. The first order conditions with respect to $y$ are

$$
\left[\lambda_{1} \frac{\partial x}{\partial y}+\left(\lambda_{2}-n c\right)\right] f(n)+\theta \frac{\partial}{\partial y}\left[\frac{\partial u}{\partial x}\left(\frac{d w}{d n}-\alpha-z \frac{d q}{d n}\right)\right]=0
$$

for $n<\hat{n}$ and

$$
\left[\lambda_{1} \frac{\partial x}{\partial y}+\left(\lambda_{3}-(\bar{n}-n) c\right)\right] f(n)+\theta \frac{\partial}{\partial y}\left[\frac{\partial u}{\partial x}\left(\frac{d w}{d n}-\alpha-z \frac{d q}{d n}\right)\right]=0
$$

for $n>\hat{n}$.

The first order condition with respect to $z$ is

$$
\left[\lambda_{1} \frac{\partial x}{\partial z}+\lambda_{4}\right] f(n)+\theta \frac{\partial}{\partial z}\left[\frac{\partial u}{\partial x}\left(\frac{d w}{d s}-\alpha-z \frac{d q}{d s}\right)\right]=0
$$

The first order condition with respect to $\alpha$ is

$$
\lambda_{5} f(n)-\theta(n) \frac{\partial u}{\partial x} \leq 0 ; \alpha\left[\lambda_{5} f(n)-\theta(s) \frac{\partial u}{\partial x}\right]=0
$$

Assume that the point $\hat{n}$ is in an interval $\left(n_{1}, n_{2}\right)$ such that $f(n)$ is strictly positive, continuous and there are no mass points for $n$ in $\left(n_{1}, n_{2}\right)$. Then it follows from the continuity of the Hamiltonian that 


$$
\begin{aligned}
& \beta v+\left[\lambda_{1} x+\left(\lambda_{2}-c \hat{n}\right) y+\lambda_{4} z+\lambda_{5} \alpha\right] f(\hat{n})+\theta \frac{\partial u}{\partial x}\left(\frac{d w}{d n}-\alpha-z \frac{d q}{d n}\right) \\
& =\beta v+\left[\lambda_{1} x+\left(\lambda_{3}-c(\bar{n}-\hat{n})\right) y+\lambda_{4} z+\lambda_{5} \alpha\right] f(\hat{n})+\theta \frac{\partial u}{\partial x}\left(\frac{d w}{d n}-\alpha-z \frac{d q}{d n}\right)
\end{aligned}
$$

so

$\left(\lambda_{2}-c \hat{n}\right)=\left(\lambda_{3}-c(\bar{n}-\hat{n})\right)$

Since $X_{1}, Y_{3}, Y_{4}$ and $Z_{3}$ are not in the Hamiltonian, $\frac{d \lambda_{i}}{d n}=0, i=1,4$.

The first order conditions for the aggregate variables in (22) are

(38) $\delta_{1} \frac{\partial F}{\partial Y_{2}}-\delta_{2} \leq 0 ; Y_{2}\left[\delta_{1} \frac{\partial F}{\partial Y_{2}}-\delta_{2}\right]=0$

(39) $\delta_{1} \frac{\partial F}{\partial Z_{2}}-\delta_{3} \leq 0 ; Z_{2}\left[\delta_{1} \frac{\partial F}{\partial Z_{2}}-\delta_{3}\right]=0$

(40) $\delta_{1}=1$

(41) $\delta_{1} p=\delta_{2}$

(42) $\delta_{1} \bar{q}=\delta_{3}$

These first order conditions are the transversality conditions for $G, X_{1}, Y_{3}$ and $Z_{3}$ :

(43) $\lambda_{1}=-1$

(44) $\lambda_{2}=-\delta_{2}=-p$

(45) $\lambda_{4}=-\delta_{3}=-\bar{q}$

Since $v(0)$ and $v(\bar{n})$ are free end points, $\theta(0)=\theta(\bar{n})=0$. The value of $\lambda_{3}$ is derived from (23) and results in

$\lambda_{3}=-p-2 c \hat{n}+c \bar{n}$

\subsection{Proof of propositions (1) through (3)}

Proposition 1 The optimal non-linear price schedule for natural gas is the netback rule. Proof 
$v(0)$ and $v(\bar{n})$ are free endpoints so $\theta(0)=\theta(\bar{n})=0$ at 0 and $\bar{n}$. Since $\lambda_{5}$ is constant, $\lambda_{5}$ is 0 for all $n$ and if $\alpha \neq 0$ then $\theta(n)=0$. Now suppose $\alpha=0$ and $\theta(n) \neq 0$, then since the Hamiltonian is linear in $\alpha$, this would violate the necessary conditions of the Maximum Principle that the Hamiltonian be maximized with respect to the control variables and thus $\theta(n)=0$ for all $\mathrm{n}$. The first order condition given by (33) can be written as

(46) $-\frac{\partial x}{\partial y}-(p+n c)=0$

so that the marginal rate of substitution equals the netback price, which is the desired result.

Proposition 2 If there are no income effects, the optimal non-linear price schedule for natural gas is the netback rule and it is independent of redistribution.

Proof:

A sufficient condition for the result to hold is that in the first order condition given by (33), the term $\theta \frac{\partial}{\partial y}\left[\frac{\partial u}{\partial x}\left(\frac{d w}{d n}-\alpha-z \frac{d p}{d n}\right)\right]=0$ so that the condition $-\frac{\partial x}{\partial y}-(p+n c)=0$ holds.

Denote derivatives by subscripts, then

$$
\frac{\partial}{\partial y} u_{x}=u_{x y}+u_{x x} \frac{\partial x}{\partial y}=u_{x y}-u_{x x} \frac{u_{y}}{u_{x}}=u_{x}\left[\frac{u_{x y} u_{x}-u_{x x}-u_{y}}{u_{x}^{2}}\right]
$$

This is the income effect term from Slutsky's equation. Further, since all individuals have the same welfare weights and there are no income effects the aggregate welfare function is not sensitive to redistribution. Proof

Proposition 3 The netback rule for pricing natural gas is Pareto optimal.

A sufficient condition for the result to hold is that the welfare weights, $\beta(n)$ be such that the term $\theta(n)=0$ for all $n$ in $[0, \bar{n}]$. Since $v(0)$ is a free endpoint, $\theta(0)=0$ so a sufficient condition for the term $\theta(n)=0$ for all $n$ in $[0, \bar{n}]$ is that

$$
\frac{d \theta}{d n}=-\left[\beta(n)-\frac{d x}{d v}\right] f(n)-\theta \frac{\partial}{\partial v}\left[\frac{\partial u}{\partial x}\left(\frac{d w}{d n}-\alpha-z \frac{d q}{d n}\right)\right]=0
$$

so

(49) $\left[\beta(n)-\frac{\partial x(s)}{\partial v(s)}\right]=0$ 
is a sufficient condition for $\theta(n)=0$ for all $n$ and the welfare weights are such that no redistribution is optimal. This implies that any redistribution cannot be Pareto improving and thus the solution is Pareto optimal. 